\title{
Risk factors of impaired fasting glucose and type 2 diabetes in Yaoundé, Cameroon: a cross sectional study
}

Clement Nyuyki Kufe ${ }^{1,2^{*}}$, Kerstin Klipstein-Grobusch ${ }^{1,3}$, Fezeu Leopold ${ }^{4}$, Felix Assah², George Ngufor ${ }^{2}$, George Mbeh², Vivian Nchanchou Mbanya ${ }^{2,5}$ and Jean Claude Mbanya ${ }^{2}$

\begin{abstract}
Background: The prevalence of diabetes is increasing worldwide, particularly in low and middle income countries, where treatment and control are often unavailable and inaccessible. Information on risk factors at local and regional levels is of utmost importance for tailored prevention programmes to curb the rise in diabetes.

The current study was undertaken to investigate the prevalence of Impaired Fasting Glucose (IFG)/Type 2 Diabetes (T2D) and its risk factors in the adult population in Biyem-Assi-Yaoundé, Cameroon.

Methods: Information on cardiovascular risk factors using the WHO STEPwise approach was obtained for 1623 men and women aged 25 years and older of the CAMBoD Project in Biyem-Assi, Yaoundé, Cameroon. T2D was defined as fasting capillary glucose (FCG) $\geq 7.0 \mathrm{mmol} / \mathrm{l}$ and/or being on diabetes medication, IFG/T2D as FCG $\geq 6.1 \mathrm{mmol} / \mathrm{l}$ and/or being on diabetes medication. Descriptive statistics and multivariate logistic regression analyses were used to describe prevalence of IFG/T2D, prevalence of risk factors for IFG/T2D and to investigate the association of risk factors with prevalence of $\mathrm{IFG} / \mathrm{T} 2 \mathrm{D}$.
\end{abstract}

Results: Prevalence of T2D and of IFG/T2D was 3.3\% and 5.7\%. Prevalence of hypertension, obesity and abdominal obesity (elevated waist circumference) was $26.6 \%, 28.4 \%$ and $34.9 \%$, respectively. Age and abdominal obesity were significantly associated with IFG/T2D in multivariate logistic regression.

Conclusion: For successful primary prevention of T2D in the general population in Cameroon tailored efforts to address obesity, particularly abdominal obesity, and associated life-style factors are warranted.

Keywords: Diabetes, Impaired fasting glucose, Prevention, Non-communicable diseases, Low and middle income countries

\section{Background}

Prevalence of type 2 diabetes (T2D) in both developed and developing countries is expected to increase dramatically from 246 million people (6.0\%) aged 20 to 79 in 2007 [1] to 382 million in 2013 and to a projected 592 million people by 2035 [2]. About 175 million people with diabetes are undiagnosed. Diabetes caused 5.1 million deaths in 2013 and impact considerably on people

\footnotetext{
* Correspondence: kufekle@yahoo.co.uk

'Division of Epidemiology \& Biostatistics, School of Public Health, Faculty of Health Sciences, University of the Witwatersrand, Johannesburg, South Africa ${ }^{2}$ Health of Populations in Transition (HoPiT) Research Group, Faculty of Medicine and Biomedical Sciences, The University of Yaoundé 1, Yaoundé, Cameroon

Full list of author information is available at the end of the article
}

under the age of 60 years. In Africa, $76.0 \%$ of deaths due to diabetes affected this age group [2]. The burden of T2D is particularly high in low and middle income countries [1-4]; for Africa prevalence of T2D was 4.5\% in $2011,5.7 \%$ in 2013 and is projected to increase to $6.0 \%$ by 2035 with the highest projected increase $(109.6 \%)$ in the number of adults aged 20-79 years [2]. For Cameroon prevalence of T2D was $0.8 \%$ in 2003, projections for 2030 estimate diabetes prevalence to be $4.8 \%$ $[5,6]$. The rapid urbanisation in sub-Saharan Africa coupled with sedentary lifestyle and increased adiposity in urban areas is a major determinant in the increasing prevalence of diabetes and cardiovascular diseases. Urban residence is associated with a more than twice 
increased risk of diabetes or IFG [4]. IFG identifies risk state for future diabetes, cardiovascular disease and premature mortality. Determining IFG in asymptomatic individuals allows for prevention strategies to be implemented that can delay or prevent onset of T2D. Overall a prevalence of $5.0 \%$ and more for IFG has been observed, varying across different age groups and between populations [5]. Age-adjusted prevalence of IFG in World Health Organisation's African region was 9.7\% in 2011 as compared to global estimates of 6.5\%. [5].

T2D is responsible for major contemporary causes of morbidity and mortality including cardiovascular diseases (CVD), retinopathies, nephropathies and neuropathies. Fifty percent of people living with T2D die of cardiovascular disease [2]. Most of T2D cases could be controlled and prevented via lifestyle modification. Factors that affect the onset of T2D are well known, such as age, ethnicity and modifiable risk factors like obesity, physical inactivity, dietary intake, tobacco and excessive alcohol consumption [6,7], though their prevalence and thus prevention potential may differ according to geographical and cultural context. IFG indicates above normal fasting blood glucose levels but lower than threshold for diagnosis of diabetes. IFG is a strong risk marker for the development of diabetes and associated with increased CVD risk [8]. Previous studies showed that during the five years preceding a diagnosis of T2D, $60.0 \%$ of people showed IFG or Impaired Glucose Tolerance (IGT) [9]. Screening for diabetes is not different from screening for IFG and the same risk factors associated with diabetes are associated with IFG [10]. Thus targeting individuals with IFG/T2D for prevention and control is of major importance to delay and/or prevent the onset of diabetes and complications which are a major cause of morbidity and mortality and highly related to duration, chronic levels of glycaemia and other risk factors.

The current study was undertaken to investigate the prevalence of modifiable risk factors and their association with IFG/T2D to guide primary prevention and control of IFG/T2D in an urban population in Cameroon.

\section{Methods}

\section{Study population}

A population-based survey to evaluate the burden of diabetes was conducted in Biyem-Assi, Yaoundé, Cameroon, in 2007 as part of the Cameroon Burden of Diabetes Project (CAMBoD), a multidisciplinary programme contributing to surveillance, prevention and control of diabetes in urban areas [11]. Biyem Assi health district had 9.7\% of health facilities of the centre region, Republic of Cameroon, which comprised $25.1 \%$ of health facilities of the country in 2011 [12]. Biyem Assi, an urban area, with most inhabitants being government or private sector workers earning a salary, business men and women or students, has previously been shown to represent the urban population in Yaoundé [13]. Based on a census enlisting all adults aged 25 years and above living in the CAMoD study area in Biyem-Assi, Yaoundé participants were invited to participate in the 2007 survey. Multilevel systematic cluster sampling stratified by age group was used, a cluster being a household. The first household was selected randomly. Individual age group sampling was done by which every age group was represented thus avoiding having the sample size of the most populated age group within a limited spatial surface. Survey participation rate was $82.5 \% \quad(n=2062)$. Participants without the main dependent variable (FCG) were excluded from the analyses resulting in an analytic study sample of 1623 study participants.

\section{Data collection and management}

Teams of four trained interviewers, each including a medical doctor, collected information on participants' self-reported behavioural and lifestyle factors for chronic diseases, blood pressure, anthropometry measurements and blood samples for biochemical analysis from September to October 2007 using standardized procedures. For quality control purposes calibrated instruments were used and adherence of trained interviewers to standardised procedures was monitored.

Participants were asked to fast overnight. For measurement of fasting capillary glucose (FCG), study participants, who had not eaten or drank anything (except plain water) for at least eight hours were visited at home between 5:30 am and 9:00 am the next day. Assessment of IFG/T2D was based on fasting capillary glucose measurements with $\mathrm{HemoCue}^{\circ} \mathrm{B}$-Glucose photometer, a validated instrument shown to give consistent readings as compared to other instruments [14]. The participant's middle or ring finger, not bearing a ring, was cleaned with an alcohol swab and pricked at the side with a lancet. Blood was collected with a microcuvette, placed into a cuvette holder and results displayed immediately [15]. HemoCue ${ }^{\circ} \mathrm{B}-$ Glucose photometers were controlled every morning. Every sixth consecutive participant screened negative was administered an oral glucose tolerance test to ascertain reliability of results for FCG. IFG/T2D was defined as fasting capillary glucose (FCG) $\geq 6.1 \mathrm{mmol} / \mathrm{l}$ and/or on diabetes medication (insulin and/or antidiabetic drugs) [8], participants with FCG between $6.1 \mathrm{mmol} / \mathrm{l}$ and $6.9 \mathrm{mmol} / \mathrm{l}$ were considered to have IFG, and those with FCG $\geq 7.0 \mathrm{mmol} / \mathrm{l}(126 \mathrm{mg} / \mathrm{dl})$ and/ or on diabetes medication (insulin and/or anti-diabetic drugs) were considered to have diabetes.

The World Health Organisation (WHO) STEPwise approach, a standardized questionnaire for chronic disease 
risk factor surveillance [16] including questions on diabetes and hypertension status (if diabetic or hypertensive and whether on diabetes or hypertensive medication (insulin and/or oral remedy)), smoking habits, alcohol intake, dietary intake and physical activity was applied by interviewers trained in the standardized administration of questionnaires in both English and French, the official languages in Cameroon. Participants previously on anti-diabetes medication and with FCG $<6.1 \mathrm{mmol} / \mathrm{l}$ and, participants informed by a health professional that $\mathrm{s} /$ he was diabetic but on local anti-diabetic remedy were excluded. The instruments for the survey were pretested and revised if indicated prior to the commencement of the survey.

Systolic (SBP) and diastolic (DBP) blood pressure was measured using fully automated calibrated Omron M3 machines with the participant being seated for at least five minutes, legs uncrossed and the left arm resting on a table prior to taking measurements. Blood pressure was measured thrice, the mean of the second and third measurement was considered for this study. Participants with mean SBP $\geq 140$ and/or DBP $\geq 90 \mathrm{mmHg}$ and/or on hypertensive medication were considered to be hypertensive [17].

Anthropometric measurements, including weight (to the nearest $0.1 \mathrm{~kg}$, SECA scales), height (to the nearest $0.1 \mathrm{~cm}$, locally made wood stadiometers), waist and hip circumferences (to the nearest $0.1 \mathrm{~cm}$, flexible inelastic fibreglass meter band), were performed using standard methods. Waist circumference was measured over light clothing at the level of the midpoint between the inferior margin of the last rib and the crest of the ilium in the mid-axillary plane. Hip circumference was measured at the level of the greater trochanter of the femur, -around the buttocks through the symphysis pubis.

Obesity and central obesity were assessed by body mass index (BMI), waist-to-hip ratio (WHR) and waist circumference (WC). BMI was calculated as weight $(\mathrm{kg})$ divided by squared height $\left(\mathrm{m}^{2}\right)$ and used to define normal weight $\left(18.5 \mathrm{~kg} / \mathrm{m}^{2} \leq \mathrm{BMI}<25 \mathrm{~kg} / \mathrm{m}^{2}\right)$, overweight $\left(25 \mathrm{~kg} / \mathrm{m}^{2} \leq \mathrm{BMI}<30 \mathrm{~kg} / \mathrm{m}^{2}\right)$ and obesity $\left(\mathrm{BMI} \geq 30 \mathrm{~kg} / \mathrm{m}^{2}\right)$ $[18,19]$. WHR was calculated as waist $(\mathrm{cm})$ divided by hip $(\mathrm{cm})$ circumference. Presence of abdominal obesity was considered in case of elevated WHR ( $>1.0$ for men and $>0.85$ for women, respectively) or elevated waist circumference (WC) $(>102 \mathrm{~cm}$ for men and $88 \mathrm{~cm}$ for women, respectively) [20-22].

Using the WHO STEPwise approach vigorous physical activity was defined as sustained activity that results in a significant increase in heart and breathing rate for at least ten minutes at a time such as forestry, digging construction, farm work or sporting activity. Moderate intensity physical activity was defined as activity that results in breathing somewhat harder than normal for at least ten minutes such as cleaning, washing, planting and harvesting crops, weaving, woodwork, brisk or quick walking or carrying of light loads. Low intensity physical activity was defined as involving mostly sitting or standing with walking for not more than ten minutes [23].

In addition, information on socioeconomic and demographic data, data on past and current medical history of diabetes and its risk factors (tobacco smoking, alcohol consumption, dietary habits, and physical activity) was obtained from all study participants.

\section{Data analysis}

Means and standard deviations (SD) were used to describe continuous variables. Logistic regression was used to investigate the association of demographic and anthropometric characteristics, blood pressure and lifestyle risk factors to IFG/T2D. Sex, marital status and variables significantly associated (two sided p-value $<0.05$ ) with IFG/T2D in univariate analyses were subsequently included in multivariate logistic regression analyses. Results were reported as Odds Ratios (OR) with corresponding 95\% confidence intervals $(95 \% \mathrm{CI})$. Statistical correlations for the presence of IFG/T2D were assessed between WHR and BMI, BMI and waist circumference, and between sex and markers of central obesity and BMI. Separate models were considered in case of correlation between variables. We carried out direct age standardisation using World Health Organisation New World Population as reference [24]. Regression analysis took into consideration stratification, proportional weights and clustering for participants with main dependent variable having complete data. All statistical analyses were adjusted for the cluster random sampling design by use of the statistical software package STATA/IC (version 11.1).

\section{Ethical considerations}

Prior to study inclusion participants gave informed consent by either signing or thumb printing on the informed consent form, a copy of which was given to the participant. Information obtained from individuals and households and results of the physical and biochemical examinations were kept confidential. All participants received individual feedback on the results of their examinations and were referred where necessary to Biyem-Assi hospital-Yaoundé for appropriate follow up. Data were anonymized for statistical analysis. Ethical clearance for the CAMBoD study was obtained from the Cameroon National Ethics Committee; Yaoundé, Cameroon; ethical clearance for analysis of the 2007 survey was given by the Human Research Ethics Committee (Medical) of the University of the Witwatersrand, Johannesburg, South Africa. 


\section{Results}

Demographic and socio-economic characteristics of study participants

The study sample comprised 1623 participants, 666 men (41.1\%) and 957 women (58.9\%). Average age was 39.7 (SD 12.9) years at the time of the survey in 2007. Demographic characteristics, i.e. marital status, educational attainment and information on occupation are given in Table 1.

Prevalence of IFG/Type 2 diabetes, hypertension and obesity Prevalence of T2D was $3.3 \% \quad(\mathrm{n}=54), 4.2 \% \quad(\mathrm{n}=28)$ among men and $2.7 \%(\mathrm{n}=26)$ among women. Figures for IFG/T2D were $5.7 \%(n=93)$, respectively $6.8 \%(n=$ $45)$ in men and $5.0 \%(n=48)$ in women. Mean FCG was $5.4 \mathrm{mmol} / \mathrm{l}$. IFG/T2D prevalence increased with age (Table 2). Thirty-one (57.4\%) of the 54 respondents considered to have T2D reported diabetes treatment; $42.6 \%$ were newly diagnosed cases. Diabetes control was poor: $42.0 \%$ of diabetics on treatment had FCG $\geq 6.1 \mathrm{mmol} / \mathrm{l}$, $29.0 \%$ had FCG $\geq 7.0 \mathrm{mmol} / \mathrm{l}$.

Prevalence of hypertension was $26.6 \%$ and significantly higher in older age groups (Table 2). Of the 432 participants considered to be hypertensive, 93 (21.5\%) participants reported receiving treatment and 45 (10.4\%) had controlled blood pressure. The majority of study participants were overweight $(34.5 \%)$ or obese $(28.4 \%)$. Average BMI of the study population was $27.6 \mathrm{~kg} / \mathrm{m}^{2}$ (SD 5.4)) and was lower in men $\left(25.9\right.$ (SD4.1) $\mathrm{kg} / \mathrm{m}^{2}$ than women (28.7 (SD 5.8) kg/m ${ }^{2}$. Women were more often obese (37.0\%) than men (16.1\%); obesity was most prevalent in the age group 45-54 years. More than a third of the study participants (36.6\%) showed elevated WHR, slightly more pronounced in men $(37.8 \%)$ than women (35.7\%). Elevated waist circumference was present in $34.9 \%$ of the study participants and was four times as high in women $(50.6 \%)$ as in men $(12.5 \%)$. For both parameters of central obesity a significant relation with age was observed.

\section{Prevalence of lifestyle factors - tobacco consumption,} alcohol consumption, physical activity and dietary habits Most survey respondents were non-smokers (75.3\%), $7.7 \%$ reported to be current smokers, the majority of them being men (89.1\%). Prevalence of current smoking was most pronounced in the age group 35-44 years, older age groups tended to report less current smoking. On average current smokers started smoking at 21.2 (SD $5.9)$ years. Less than a third (28.\%) of those who reported to have smoked previously indicated to have stopped because of health related problems; on average they reported to have quit smoking at age 34.7 (SD 11.1) years.

Alcohol consumption was common with $65.5 \%$ of participants reporting current alcoholic beverage consumption such as beer, wine, spirit or local brews as palm wine, corn beer, "bilibili", "arki" or "afofo" and was most prominent in those aged 25-34 years (men 91.2\%, women $78.5 \%$ ). Men more often reported current alcohol consumption than women and were less often abstainers. Beer was the most consumed alcoholic drink, specifically in men (70.9\%, women $49.8 \%)$ followed by consumption of wine, palm wine, whisky, "bilibili" or corn beer and "arki".

Most respondents (61.5\%) reported physical activity, mostly low intensity physical activity (51.8\%). Vigorous physical activity was only reported by $4.3 \%$ of the participants. In general, intense physical activities were reported more often by younger age groups and more often by men than women (data not shown). For leisure/ recreational activities most study participants (85.9\%) reported light activities, vigorous intensity was only reported by $6.1 \%$ of the study participants.

On average fruit consumption was reported on 3 days/ week, vegetable consumption on 2.4 days/week; less than $2.5 \%$ of respondents reported any vegetable consumption, whereas $13.4 \%$ did not report any fruit consumption. Older women reported highest fruit consumption.

\section{Risk factors for IFG/T2D}

Diabetic participants were often older, obese, hypertensive, had elevated waist circumference and WHR, and were less often single and more often retired (Table 1). Age was significantly associated with IFG/T2D (Table 3). Being obese was associated with increased likelihood of IFG/T2D when compared to normal weight participants (OR: 2.24, 95\% CI: 1.33-3.78). Both markers of abdominal obesity were associated with IFG/T2D, OR for elevated WHR was 2.91 (95\% CI: 1.99-4.25), OR for high waist circumference was 2.23 (95\% CI: 1.45-3.46). Hypertension $(\mathrm{OR}=2.11,95 \% \mathrm{CI}: 1.42-3.13)$ was also associated with IGF/T2D (Table 3).

Gender and all variables significantly associated with IFG/T2D in univariate models were included in multivariate logistic regression models to further analyse the association with IFG/T2D. The two markers of abdominal obesity were considered in separate multivariate logistic regression analysis due to their high correlation. Both markers were highly associated with IFG/T2D in multivariate adjusted models. Hosmer-Lemeshow goodnessof-fit test confirmed the appropriateness of the two multivariate adjusted models.

The factors that maintained their statistical significance after multivariate adjustment were age (35-44 years: $\mathrm{OR}=2.63,95 \% \mathrm{CI}: 1.26-5.51, \mathrm{p}=0.010 ; 45-54$ years: $\mathrm{OR}=3.05,95 \% \mathrm{CI}: 1.50-6.22, \mathrm{p}<0.002$ and $55-64$ years: $\mathrm{OR}=5.88,95 \% \mathrm{CI}: 2.59-13.37, \mathrm{p}<0.001)$ and elevated WHR $(\mathrm{OR}=2.21,95 \% \mathrm{CI}: 1.22-4.01, \mathrm{p}=0.009)$ (Table 3). 
Table 1 Description of study participants according to IFG/T2D status, Yaoundé, Cameroon, 2007

\begin{tabular}{|c|c|c|c|c|c|c|c|}
\hline \multirow[t]{3}{*}{ Variable } & \multirow{2}{*}{\multicolumn{2}{|c|}{$\frac{\text { All }}{(n=1623)}$}} & \multirow{2}{*}{\multicolumn{2}{|c|}{$\begin{array}{l}\text { IFG/T2D } \\
(n=93)\end{array}$}} & \multirow{2}{*}{\multicolumn{2}{|c|}{$\begin{array}{l}\text { Non IFG/T2D } \\
(n=1530)\end{array}$}} & \multirow[t]{3}{*}{ P-value* } \\
\hline & & & & & & & \\
\hline & $\mathrm{N}$ & $\%$ & $n$ & $\%$ & $\mathrm{~N}$ & $\%$ & \\
\hline \multicolumn{8}{|l|}{ Gender } \\
\hline Male & 666 & 41.0 & 55 & 45.1 & 611 & 40.7 & \\
\hline Female & 957 & 59.0 & 67 & 54.9 & 890 & 59.3 & 0.345 \\
\hline \multicolumn{8}{|l|}{ Age group (years) } \\
\hline $25-24$ & 768 & 47.3 & 22 & 18.0 & 746 & 49.7 & \\
\hline $35-44$ & 278 & 17.1 & 22 & 18.0 & 256 & 17.1 & \\
\hline $45-54$ & 337 & 20.8 & 38 & 31.2 & 299 & 19.9 & \\
\hline $55-64$ & 170 & 10.5 & 34 & 27.9 & 136 & 9.1 & \\
\hline $65+$ & 70 & 4.3 & 6 & 4.9 & 64 & 4.3 & $<0.001$ \\
\hline \multicolumn{8}{|l|}{ Marital status } \\
\hline Married & 852 & 52.5 & 84 & 68.9 & 768 & 51.2 & \\
\hline Single & 584 & 36.0 & 20 & 16.4 & 564 & 37.6 & \\
\hline Others & 187 & 11.5 & 18 & 14.8 & 169 & 11.3 & $<0.001$ \\
\hline \multicolumn{8}{|l|}{ Occupation $(n=1526)$} \\
\hline Civil servant/Private sector & 591 & 38.7 & 51 & 46.4 & 540 & 38.1 & \\
\hline Self-employed/unpaid subsistence farming & 259 & 16.9 & 18 & 16.4 & 241 & 17.0 & \\
\hline Student & 197 & 12.9 & 4 & 3.6 & 193 & 13.6 & \\
\hline Retired/House keeper & 288 & 18.9 & 30 & 27.3 & 258 & 18.2 & \\
\hline Unemployed & 191 & 12.5 & 7 & 6.3 & 184 & 12.9 & $<0.001$ \\
\hline \multicolumn{8}{|l|}{ Highest level of education $(n=1607)$} \\
\hline Never went to school to completed primary school & 366 & 22.8 & 31 & 25.6 & 335 & 22.5 & \\
\hline Completed secondary school & 405 & 25.2 & 30 & 24.8 & 375 & 25.2 & \\
\hline Completed high school & 391 & 24.3 & 27 & 22.3 & 364 & 24.5 & \\
\hline Completed university & 445 & 27.7 & 33 & 27.3 & 412 & 27.7 & 0.873 \\
\hline \multicolumn{8}{|l|}{ Weight status } \\
\hline Underweight to normal & 593 & 36.5 & 30 & 24.6 & 563 & 37.5 & \\
\hline Overweight & 562 & 34.6 & 42 & 34.4 & 520 & 34.6 & \\
\hline Obese & 468 & 28.8 & 50 & 41.0 & 418 & 27.9 & 0.003 \\
\hline \multicolumn{8}{|l|}{ Waist-to-hip ratio } \\
\hline$<0.90$ (men) or $<0.85$ (women) & 1029 & 63.4 & 48 & 39.3 & 981 & 65.4 & \\
\hline$>0.90$ (men) or $>0.85$ (women) & 594 & 36.6 & 74 & 60.7 & 520 & 34.6 & $<0.001$ \\
\hline \multicolumn{8}{|l|}{ Waist circumference } \\
\hline$\leq 94$ (men) $\leq 80 \mathrm{~cm}$ (women) & 743 & 45.8 & 40 & 32.8 & 703 & 46.8 & \\
\hline $94>\&<102$ (men) $80>\& 88 \mathrm{~cm}$ (women) & 313 & 19.3 & 18 & 14.8 & 295 & 19.7 & \\
\hline$\geq 102 \mathrm{~cm}$ (men) $\geq 88 \mathrm{~cm}$ (women) & 567 & 34.9 & 64 & 52.4 & 503 & 33.5 & $<0.001$ \\
\hline \multicolumn{8}{|l|}{ Hypertension } \\
\hline Yes & 432 & 26.6 & 51 & 41.8 & 381 & 25.4 & \\
\hline No & 1191 & 73.4 & 71 & 48.2 & 1120 & 74.6 & $<0.001$ \\
\hline \multicolumn{8}{|l|}{ Smoking $(n=1607)$} \\
\hline Never & 1219 & 75.9 & 91 & 75.8 & 1128 & 75.9 & \\
\hline Former & 266 & 16.5 & 19 & 15.8 & 247 & 16.6 & \\
\hline Current & 122 & 7.6 & 10 & 8.3 & 112 & 7.5 & 0.935 \\
\hline
\end{tabular}


Table 1 Description of study participants according to IFG/T2D status, Yaoundé, Cameroon, 2007 (Continued)

\begin{tabular}{|c|c|c|c|c|c|c|c|}
\hline \multicolumn{8}{|c|}{ Alcohol consumption } \\
\hline Never & 269 & 16.7 & 19 & 15.6 & 250 & 16.7 & \\
\hline Former & 293 & 18.2 & 23 & 18.9 & 270 & 18.1 & \\
\hline Current & 1051 & 65.1 & 80 & 65.5 & 971 & 65.1 & 0.935 \\
\hline \multicolumn{8}{|c|}{ General physical activity } \\
\hline None & 628 & 38.6 & 37 & 30.3 & 591 & 39.4 & \\
\hline Low intensity & 837 & 51.6 & 73 & 59.8 & 764 & 50.9 & \\
\hline Moderate activity & 87 & 5.4 & 4 & 3.3 & 83 & 5.5 & \\
\hline Vigorous activity & 71 & 4.4 & 8 & 6.6 & 63 & 4.2 & 0.084 \\
\hline \multicolumn{8}{|c|}{ Walking/cycling for at least 10 minutes $(n=1609)$} \\
\hline Yes & 1339 & 83.2 & 96 & 80.7 & 1243 & 83.4 & \\
\hline No & 270 & 16.8 & 23 & 19.3 & 247 & 16.6 & 0.440 \\
\hline \multicolumn{8}{|c|}{ Activity during recreation/leisure $(n=1614)$} \\
\hline None & 89 & 5.5 & 2 & 1.7 & 87 & 5.8 & \\
\hline Low intensity & 1394 & 86.4 & 105 & 88.2 & 1289 & 86.2 & \\
\hline Moderate activity & 42 & 2.6 & 4 & 3.4 & 38 & 2.5 & \\
\hline Vigorous activity & 89 & 5.5 & 8 & 6.7 & 81 & 5.4 & 0.251 \\
\hline \multicolumn{8}{|c|}{ Fruit consumption/week $(n=1471)$} \\
\hline 0/day & 299 & 20.3 & 26 & 22.0 & 273 & 20.2 & \\
\hline $1-2$ days & 252 & 17.1 & 29 & 24.6 & 223 & 16.5 & \\
\hline 3-4 days & 731 & 49.7 & 44 & 37.3 & 687 & 50.8 & \\
\hline 5-7 days & 189 & 12.9 & 19 & 16.1 & 170 & 12.5 & 0.025 \\
\hline \multicolumn{8}{|c|}{ Vegetable consumption/week $(n=1555)$} \\
\hline $1-2$ days & 183 & 11.8 & 19 & 16.1 & 164 & 11.4 & \\
\hline 3-4 days & 407 & 26.1 & 37 & 31.4 & 370 & 25.8 & \\
\hline 5-7 days & 965 & 62.1 & 62 & 52.5 & 903 & 62.8 & 0.074 \\
\hline
\end{tabular}

${ }^{*}$ Chi-square test for comparison of distribution of variable categories for IFG/T2D versus non IFG/T2D.

\section{Discussion and conclusions}

The current study assessed the prevalence of and the risk factor profile for IFG/T2D in the general adult population in Biyem-Assi, Yaoundé, Cameroon and observed age and central obesity to be the most important risk factors associated with prevalence of IFG/T2D.

An increase in the prevalence of diabetes in this urban area was observed from $2.0 \%$ in 1999 [4] to $3.3 \%$ in 2007. Regional and comparative prevalence in Africa was $4.9 \%$ and $5.7 \%$ respectively and ranged from $4.4 \%$ to $7.0 \%$ in 2013 depending on the country's economic development [25]. A higher urban prevalence for diabetes was observed in Tanzania for Asian Indians in 1991 (9.1\%) and South Africa for Native Africans in 1993 (8.0\%) [4].

In Zambia, the combined prevalence of impaired glucose levels or diabetes in 2011 was $4.0 \%$ (impaired glucose levels or diabetes defined as fasting glucose $\geq$ $5.51 \mathrm{mmol} / \mathrm{l}$ ) [26], higher than for this study most likely due to a lower cut off point for IFG levels. A similar study in China using the same cut off points for IFG and T2D as in our study showed a higher prevalence of diagnosed diabetes, undiagnosed diabetes and IFG in adults respectively; $1.3 \%, 4.2 \%$ and $7.3 \%$ [27], possibly in part due to increased levels of physical inactivity, high levels of alcohol consumption and poor dietary habits. Beneficial effects of lifestyle behaviour to prevent or delay the onset of diabetes and other health related benefits have been demonstrated [28-30]. Prevalence estimates observed in the current study were lower than estimates for diabetes mellitus (5.7\%) and IFG (4.5\%) reported by a systematic review and meta-analysis in sub-Saharan Africa published in 2013 [31]. Disparities in prevalence are probably in part due to differences in health determinants across sub-Saharan Africa [31]. IFG is a risk state prior to diabetes and ideally diabetes prevention strategies identify and focus on individuals at pre-diabetes state. Newly diagnosed cases represented $42.6 \%$ in our study in contrast to more than $70 \%$ of newly diagnosed cases reported for surveys [4]. This difference can be 
Table 2 Percentage description of type 2 diabetes (T2D), Impaired fasting glucose (IFG)/T2D, hypertension, waist-hip-ratio, waist circumference and body mass index by age group and by gender among 1623 study participants in Yaoundé, Cameroon, 2007

\begin{tabular}{|c|c|c|c|c|c|c|c|c|c|c|c|c|c|c|}
\hline & & \multicolumn{6}{|c|}{ Men $(n=666)$} & & \multicolumn{6}{|c|}{ Women $(n=957)$} \\
\hline & & $25-34$ & $35-44$ & $45-54$ & $55-64$ & $>65$ & p-value ${ }^{7}$ & & $25-34$ & $35-44$ & $45-54$ & $55-64$ & $>65$ & p-value ${ }^{7}$ \\
\hline $\mathbf{N}$ & 666 & 317 & 100 & 116 & 100 & 33 & & 957 & 451 & 178 & 221 & 70 & 37 & \\
\hline Variable & N (\%) & N (\%) & N (\%) & N (\%) & N (\%) & N (\%) & & N (\%) & N (\%) & N (\%) & N (\%) & N (\%) & N (\%) & \\
\hline $\mathrm{T}^{\mathrm{D}} \mathrm{D}^{1}$ & $28(4.2)$ & $3(10.7)$ & $1(3.6)$ & $8(28.6)$ & $14(50.0)$ & $2(7.1)$ & $<0.001$ & $26(2.7)$ & $4(15.4)$ & $4(15.4)$ & $10(38.5)$ & $6(23.1)$ & $2(7.7)$ & $<0.001$ \\
\hline $\mathrm{IFG} / \mathrm{T} 2 \mathrm{D}^{2}$ & $45(6.8)$ & $5(11.1)$ & $8(17.8)$ & $9(20.0)$ & $21(46.7)$ & $2(4.4)$ & $<0.001$ & $48(5.0)$ & $9(18.8)$ & $8(16.7)$ & $20(41.7)$ & $8(16.6)$ & $3(6.2)$ & $<0.001$ \\
\hline Hypertension ${ }^{3}$ & $203(30.5)$ & 37 (18.2) & $21(10.3)$ & 58 (28.6) & $59(29.1)$ & $28(13.8)$ & $<0.001$ & $229(23.9)$ & $35(15.3)$ & $24(10.5)$ & $101(44.1)$ & $43(18.8)$ & $26(11.4)$ & $<0.001$ \\
\hline \multicolumn{15}{|l|}{ Weight status ${ }^{4}$} \\
\hline Normal weight & $314(47.2)$ & $195(62.1)$ & $38(12.1)$ & $33(10.5)$ & $32(10.2)$ & $16(5.1)$ & & $279(29.2)$ & $185(66.3)$ & 38 (13.6) & $28(10.0)$ & $15(5.4)$ & $13(4.7)$ & \\
\hline Overweight & $243(36.5)$ & $95(39.1)$ & $41(16.9)$ & $54(22.2)$ & $44(18.1)$ & $9(3.7)$ & & $319(33.3)$ & $157(49.2)$ & $60(18.8)$ & $71(22.3)$ & $22(6.9)$ & $9(2.8)$ & \\
\hline Obese & 109 (16.4) & $27(24.8)$ & $21(19.3)$ & 29 (26.6) & $24(22.0)$ & $8(7.3)$ & $<0.001$ & 359 (37.5) & $109(30.4)$ & $80(22.3)$ & $122(33.9)$ & $33(9.2)$ & $15(4.2)$ & $<0.001$ \\
\hline \multicolumn{15}{|l|}{ Waist-hip-ratio ${ }^{5}$} \\
\hline Normal & $414(62.2)$ & $280(67.6)$ & $58(14.0)$ & $40(9.7)$ & $29(7.0)$ & $7(1.7)$ & & $615(64.3)$ & $340(55.3)$ & $118(19.2)$ & $116(18.9)$ & $29(4.7)$ & $12(1.9)$ & \\
\hline Elevated & $252(37.8)$ & $37(14.7)$ & $42(16.7)$ & $76(30.2)$ & $71(28.2)$ & $26(10.3)$ & $<0.001$ & $342(35.7)$ & $111(32.5)$ & $60(17.5)$ & $105(30.7)$ & $41(12.0)$ & $25(7.3)$ & $<0.001$ \\
\hline \multicolumn{15}{|c|}{ Waist circumference ${ }^{6}$} \\
\hline Normal & $485(72.8)$ & $287(59.2)$ & 64 (13.2) & $65(13.4)$ & $52(10.7)$ & $17(3.5)$ & & $258(27.0)$ & $185(71.7)$ & $40(15.5)$ & $21(8.1)$ & $8(3.1)$ & $4(1.6)$ & \\
\hline Increased risk & $98(14.7)$ & $23(23.5)$ & $17(17.4)$ & $23(23.5)$ & $28(28.6)$ & $7(7.1)$ & & $215(22.5)$ & $113(52.6)$ & $33(15.4)$ & $43(20.0)$ & $15(7.0)$ & $11(5.1)$ & \\
\hline Elevated & $83(12.5)$ & $7(8.4)$ & $19(22.9)$ & $28(33.7)$ & $20(24.1)$ & $9(10.8)$ & $<0.001$ & $484(50.6)$ & 153 (31.6) & $105(21.7)$ & $157(32.4)$ & $47(9.7)$ & $22(4.6)$ & $<0.001$ \\
\hline
\end{tabular}

${ }^{1} \mathrm{FCG}>=7.0 \mathrm{mmol} / \mathrm{l}$ and $/$ or on diabetes medication.

${ }^{2} \mathrm{FCG}>=6.1 \mathrm{mmol} / \mathrm{l}$ and $/$ or on diabetes medication.

${ }^{3} \mathrm{SBP} \geq 140$ and /or DBP $\geq 90 \mathrm{mmHg}$ and / or on hypertensive medication.

${ }^{4}$ Normal weight $\left(18.5 \mathrm{Kg} / \mathrm{m}^{2} \leq \mathrm{BMI}<25 \mathrm{Kg} / \mathrm{m}^{2}\right)$, overweight $\left(25 \mathrm{Kg} / \mathrm{m}^{2} \leq \mathrm{BMl}<30 \mathrm{Kg} / \mathrm{m}^{2}\right)$ and obese $\left(\mathrm{BMI} \geq 30 \mathrm{Kg} / \mathrm{m}^{2}\right)$

${ }^{5}$ Normal waist-hip-ratio $<1.0$ for men and $<0.85$ for women and elevated waist-hip-ratio $>1.0$ for men and $>0.85$ for women.

${ }^{6}$ Normal waist circumference $<94 \mathrm{~cm}$ for men and $<80 \mathrm{~cm}$ for women, increased risk $(94 \mathrm{~cm}>W C<102 \mathrm{~cm}$ ) for men and $(80 \mathrm{~cm}>W C<88 \mathrm{~cm})$ for women and elevated $\geq 102 \mathrm{~cm}$ for men and $\geq 88 \mathrm{~cm}$ for women. 
Table 3 Risk factors for IFG/T2D in study participants aged 25 years and older in Yaoundé, Cameroon, 2007

\begin{tabular}{|c|c|c|c|c|c|c|c|c|}
\hline \multirow[t]{2}{*}{ Factors } & \multicolumn{4}{|c|}{ Univariate logistic regression } & \multicolumn{4}{|c|}{ Multivariate logistic regression } \\
\hline & $\mathrm{OR}$ & $95 \% \mathrm{Cl}$ & $\mathbf{P}$ & $p$ for trend & $\mathrm{OR}$ & $95 \% \mathrm{Cl}$ & $\mathrm{p}$ & $p$ for trend \\
\hline \multicolumn{9}{|l|}{ Gender } \\
\hline Female & 1 & & & & 1 & & & \\
\hline Male & 1.19 & $0.82-1.74$ & 0.352 & 0.352 & 1.23 & $0.73-2.07$ & 0.443 & 0.332 \\
\hline \multicolumn{9}{|l|}{ Age Group } \\
\hline $25-34$ & 1 & & & & 1 & & & \\
\hline $35-44$ & 2.91 & $1.59-5.31$ & 0.000 & & 2.65 & $1.27-5.53$ & 0.009 & \\
\hline $45-54$ & 4.31 & 2.53-7.32 & 0.000 & & 3.04 & $1.50-6.14$ & 0.002 & \\
\hline $55-64$ & 8.48 & $4.67-15.37$ & 0.000 & & 5.69 & $2.52-12.83$ & 0.000 & \\
\hline $65+$ & 3.18 & $1.28-7.90$ & 0.013 & $<0.001$ & 1.88 & $0.60-5.86$ & 0.275 & $<0.001$ \\
\hline \multicolumn{9}{|l|}{ Marital status } \\
\hline Married & 1 & & & & & & & \\
\hline Single & 0.32 & $0.19-0.54$ & 0.000 & & & & & \\
\hline Others & 0.97 & $0.50-1.88$ & 0.937 & 0.119 & & & & \\
\hline \multicolumn{9}{|l|}{ Weight status } \\
\hline Normal & 1 & & & & 1 & & & \\
\hline Overweight & 1.52 & $0.90-2.55$ & 0.117 & & 0.92 & $0.47-1.80$ & 0.810 & \\
\hline Obese & 2.24 & $1.33-3.78$ & 0.002 & 0.002 & 1.14 & $0.56-2.34$ & 0.704 & 0.503 \\
\hline \multicolumn{9}{|l|}{ Waist-hip ratio } \\
\hline$<1.0$ (men) or $<0.85$ (women) & 1 & & & & 1 & & & \\
\hline$>1.0$ (men) or >0.85 (women) & 2.91 & $1.99-4.25$ & 0.000 & $<0.001$ & 2.21 & $1.22-4.01$ & 0.009 & 0.008 \\
\hline \multicolumn{9}{|l|}{ Waist circumference in $\mathrm{cm}$} \\
\hline$\leq 94$ (men) or $\leq 80$ (women) & 1 & & & & 1 & & & \\
\hline $94>\&<102$ (men) or $80>\&<88$ (women) & 1.07 & $0.59-1.96$ & 0.821 & & 0.71 & $0.33-1.53$ & & \\
\hline$\geq 102$ (men) or $\geq 88$ (women) & 2.23 & $1.45-3.46$ & 0.000 & $<0.001$ & 1.08 & $0.48-2.47$ & 0.850 & 0.798 \\
\hline \multicolumn{9}{|l|}{ Prevalence of hypertension } \\
\hline No & 1 & & & & 1 & & & \\
\hline Yes & 2.11 & $1.42-3.13$ & 0.000 & $<0.001$ & 1.58 & $0.92-2.72$ & 0.100 & 0.145 \\
\hline \multicolumn{9}{|l|}{ Smoking } \\
\hline Never & 1 & & & & & & & \\
\hline Former & 0.95 & $0.57-1.60$ & 0.857 & & & & & \\
\hline Current & 1.11 & $0.56-2.19$ & 0.771 & 0.888 & & & & \\
\hline \multicolumn{9}{|l|}{ Alcohol consumption } \\
\hline Never drank & 1 & & & & & & & \\
\hline Former & 1.12 & $0.57-2.21$ & 0.743 & & & & & \\
\hline Current & 1.08 & $0.65-1.81$ & 0.758 & 0.820 & & & & \\
\hline \multicolumn{9}{|l|}{ General physical activity } \\
\hline None & 1 & & & & & & & \\
\hline Low intensity & 1.53 & $0.96-2.42$ & 0.073 & & & & & \\
\hline Moderate activity & 0.77 & $0.26-2.29$ & 0.637 & & & & & \\
\hline Vigorous activity & 2.03 & $0.88-4.69$ & 0.098 & 0.111 & & & & \\
\hline
\end{tabular}


most likely attributed to on-going sensitisation campaigns in the study area to curb diabetes [12]. The observed associations of age and central obesity with IFG/ T2D in this Cameroonian population are in accordance with previous international observations [4-6], in particular central obesity was observed to be a good predictor of IFG/T2D. Waist circumference has previously been shown in a Cameroonian population to be positively associated to all obesity related abnormalities [32].

We observed no association between fruit and vegetable consumption and IFG/T2D, despite previous reports on an inverse association of these low energy density, low glycaemic load, and high fibre and micronutrient content foods with risk of developing IFG/T2D $[33,34]$. Our results may in part be explained by poor quantification of the type and amounts of fruits and vegetables consumed with the interviewer-administered questionnaire and with seasonal availability of these produce on the local market.

Likewise, we observed no associations for current and former smokers with IFG/T2D, nor an inverse association for moderate alcohol intake or physical activity with IFG/T2D [35-38] pointing towards methodological challenges of the WHO-STEPS tool applied for assessment of risk factors in this population in Cameroon. These may entail for example for physical activity, difficulties in interpretation of the physical activity questions, e.g. perception of categories of physical activity on the one side and on the other side the notion that some leisure/recreational physical activities in Cameroon are rather considered to be social occasions coupled with entertainment including alcohol and food consumption potentially offsetting the beneficial effects that accrue from physical activity.

The results reported in the current study are based on the CAMBoD survey conducted in the adult population of Biyem-Assi, Yaoundé, Cameroon in 2007. In comparison with a survey conducted in the area in 2003 increased prevalence for IFG/T2D ((3.7\% (2003) to 4.1\% (2007), hypertension (17.1\% (2003) to $20.4 \%$ (2007)) and obesity (14.6\% (2003) to $18.3 \%$ (2007); all agestandardized data) were noted. Our study showed that T2D, IFG/T2D, hypertension and adiposity affects particularly people in the age group 45-54 years. Prevalence has increased though less than for any of the top 10 countries in the African region for which increasing prevalence of $6.3 \%$ to $15.4 \%$ was reported in 2013 [25]. Urban settlements are fast becoming diabetic and obesity epi-centres and increasingly people at younger ages are observed to develop diabetes $[2,4,5]$. The high burden of diabetes in low and middle income countries especially in sub-Saharan Africa [25,31] calls for increased efforts to address individual lifestyle changes to reduce modifiable IFG/T2D risk factors [28,29], particularly central obesity, to counteract accelerating prevalence rates of IFG/T2D in a population undergoing rapid urbanisation and epidemiologic transition with limited health resources accentuated by negligible health expenditure on diabetes.

\section{Limitations and advantages of the study}

The current cross-sectional study was conducted in an urban setting in Yaoundé and may thus not be generalizable to the rural population in Cameroon. Missing information in the survey population may further limit the generalizability of the study results. For definition of pre-diabetes, we used IFG instead of IGT, which considering that FCG may potentially fail to identify previously undiagnosed diabetes, could have introduced misclassification of IFG/T2D. Participants on anti-diabetic medication were considered to be diabetic, however, some may have been prescribed anti-diabetic medication at a pre-diabetes stage, which might have resulted in some misclassification of IFG and T2D.

Despite these limitations and taking into consideration feasibility, reproducibility, acceptability and local context our study provided prevalence data of T2D, IFG/T2D, hypertension and adiposity by sex and age group strata for an urban Cameroonian population. The study seeks to enhance public awareness on the seriousness of diabetes and its complications and the need for prevention strategies especially in people less than 45 years of age.

\section{Competing interests}

The authors declare that they have no competing interests.

\section{Authors' contributions}

CNK designed the current study, conducted all detailed data analyses and drafted the manuscript. KKG was involved in the design, analysis, write-up of the study and in critically revising the manuscript. JCM provided the data, contributed to development of protocol and writing of the manuscript. LF, FA, GN, GM, VNM and JCM contributed to development of protocol, data collection and writing of manuscript. LF carried out preliminary data analysis for the whole CAMBOD survey of 2007 and commented on data analysis and interpretation. All authors have reviewed the final version of the submitted manuscript and approved it for publication. Neither this manuscript nor one with substantial similar content under our authorship has been published or is being considered for publication.

\section{Acknowledgements}

We are grateful to World Diabetes Foundation (WDF) who provided funding to Health of Populations in Transition (HoPiT) Research Group Cameroon for the Cameroon Burden of Diabetes (CAMBoD) Project on which this paper is based. We gratefully acknowledge the input of HoPiT staff, data collection and entry staff and research participants in making this study possible. Financial support to CNK from the MRCMits Rural Public Health and Health Transition Research Unit (Agincourt) for completion of a thesis for the degree of MSc (Med) in Epidemiology \& Biostatistics at the University of the Witwatersrand, on which this manuscript is based, is greatly acknowledged.

\section{Author details}

${ }^{1}$ Division of Epidemiology \& Biostatistics, School of Public Health, Faculty of Health Sciences, University of the Witwatersrand, Johannesburg, South Africa. ${ }^{2}$ Health of Populations in Transition (HoPiT) Research Group, Faculty of Medicine and Biomedical Sciences, The University of Yaoundé 1, Yaoundé, 
Cameroon. ${ }^{3}$ Julius Global Health, Julius Center for Health Sciences and Primary Care, University Medical Center Utrecht, Utrecht, The Netherlands. ${ }^{4}$ Université Paris 13, Sorbonne Paris Cité, Unité de Recherche en Epidémiologie Nutritionnelle (UREN)/U557 Inserm/U1125 Inra/Cnam/CRNH, Paris, France. ${ }^{5}$ Department of Community Medicine, University of Oslo, Oslo, Norway.

Received: 19 May 2014 Accepted: 14 January 2015

Published online: 31 January 2015

\section{References}

1. World Health Organization Global Program on Evidence for Health Policy. National burden of disease studies, A practical guide, edition 2.0. 2001.

2. International Diabetes Federation. Diabetes Atlas. 6th ed. 2013.

3. Hall V, Thomson RW, Henriksen O, Loshe N. Diabetes in Sub Saharan Africa 1999-2011: epidemiology and public health implications. A systematic review. BMC Public Health. 2011;11:564.

4. Mbanya JC, Motala AA, Sobngwi E, Assah FK, Enoru ST. Diabetes in sub-Saharan Africa. Lancet. 2010;375(9733):2254-66.

5. Definition and diagnosis of diabetes mellitus and intermediate hyperglycemia. Report of a WHO/IDF consultation. 2006.

6. International Diabetes Federation. Diabetes Atlas. 3rd ed. 2006.

7. International Diabetes Federation. Diabetes Atlas. 4th ed. 2009.

8. Unwin N, Shaw J, Zimmet P, Alberti GMM. International diabetes federation IGT/IFG consensus statement. Diabet Med. 2002;19:708-23.

9. Nathan DM, Davidson MB, DeFronzo RA, Heine RJ, Henry RR, Pratley R, et al. Impaired fasting glucose and impaired glucose tolerance. Implications of care. Diabetes Care. 2007:30(3):753-9.

10. Kamadjeu RM, Edwards R, Atanga JS, Unwin N, Kiawi EC, Mbanya JC Prevalence, awareness and management of hypertension in Cameroon: findings of the 2003 Cameroon burden of diabetes baseline survey. J Hum Hyperten. 2006;20:91-2.

11. Kiawi E, Edwards R, Shu J, Unwin N, Kamadjeu R, Mbanya JC. Knowledge, attitudes, and behavior relating to diabetes and its main risk factors among urban residents in Cameroon: a qualitative survey. Ethn Dis. 2006;16:503-9.

12. Cartographie des formations sanitaires au Cameroon. Ministry of public health Cameroon 2011. 2011

13. Sobngwi E, Mbanya J-CN, Unwin NC, Kengne AP, Fezeu L, Minkoulou EM, et al. Physical activity and its relationship with obesity, hypertension and diabetes in urban and rural Cameroon. Int J Obes. 2002:26:1009-16.

14. Ashworth L, Gibb I, Alberti KGMM. HemoCue: evaluation of a portable photometric system for determining glucose in whole blood. Clin Chem. 1992;38:1479-82.

15. HemoCue ${ }^{\mathrm{TM}} \mathrm{Hb}$ 201DM System Photometer Operating Manual. Angelhom Sweden: HemoCue AB; 2005.

16. World Health Organization. WHO STEPS surveillance manual: the WHO STEPwise approach to chronic disease risk factor surveillance. Geneva: World Health Organization; 2005.

17. Chobanian AV, Bakris GL, Black HR, Cushman WC, Green LA, Izzo Jr JL, et al. The seventh report of the joint national committee on prevention, detection, evaluation, and treatment of high blood pressure: the JNC7 report (published correction appears in JAMA;290[2]:197). JAMA. 2003:289:2560-72

18. Gallagher D, Visser M, Sepulveda D, Pierson RN, Harris T, Heymsfield SB. How useful is body mass index for comparison of body fatness across age, sex, and ethnic groups? Am J Epidemiol. 1996;143:228-39.

19. WHO. Physical status: the use and interpretation of anthropometry, Report of a WHO expert committee. WHO technical report series 854. 1995.

20. WHO. Obesity: preventing and managing the global epidemic, Report of a WHO consultation. WHO technical report series 894. 2000

21. Östman J, Britton M, Jonsson E. Treating and preventing obesity. Kga, Weinheim: WILEY-VCH Verlag GmbH \& Co; 2004.

22. Mamtani MR, Kulkarni HR. Predictive performance of anthropometric indexes of central obesity for the risk of type 2 diabetes. Arch Med Res. 2005:3:581-9.

23. Centers for Disease Control and Prevention (CDC). Physical Activity Terms. Available at: http://www.cdc.gov/nccdphp/dnpa/physical/terms/index.htm. Accessed September 15, 2013.

24. Ahmad OB, Boschi-Pinto C, Lopez AD, Murray CJL, Lozano R, Inoue M. Age standardization of rates: a New WHO standard. GPE discussion paper series: No.31. Geneva: World Health Organisation; 2001.
25. Peer N, Kengne AP, Motala AA, Mbanya JC. Diabetes in the Africa region: an update. Diabetes Res Clin Pract. 2013;103:197-205.

26. Nsakashalo-Senkwe M, Siziya S, Goma FM, Songolo P, Mukonka V, Babaniyi O. Combined prevalence of impaired glucose level or diabetes and its correlates in Lusaka Urban district. Zambia: a population based survey. Int Arch Med. 2011;4:2.

27. Gu D, Reynolds K, Duan X, Xin X, Chen J, Wu X, et al. Prevalence of diabetes and impaired fasting glucose in the Chinese adult population: International Collaborative Study of Cardiovascular Disease in Asia (InterAsia). Diabetologia. 2003;46:1190-8.

28. Tuomilehto J, Lindström J, Eriksson JG, Valle TT, Hamalainen H, llanne-Parikka P, et al. Prevention of type 2 diabetes mellitus by changes in lifestyle among subjects with impaired glucose tolerance. New Engl J Med. 2001;344:1343-50.

29. Knowler WC, Barrett-Connor E, Fowler SE, Hammon RF, Lachin JM, Walker EA, et al. Reduction in the incidence of type 2 diabetes with life style intervention or metformin. N Engl J Med. 2002;346:393-403.

30. Cowie CC, Rust KF, Byrd-Holt DD, Flegal KM, Engelgau MM, Saydah SH, et al. Prevalence of diabetes and impaired fasting glucose in adults in the US population: national health and nutrition examination survey 1999-2002. Diabetes Care. 2006;29:1263-8.

31. Hilawe EH, Yatsuya H, Kawaguchi L, Aoyama A. Differences by sex in the prevalence of diabetes mellitus, impaired fasting glycemia and impaired glucose tolerance in sub-Saharan Africa: a systematic review and meta-analysis. Bull World Health Organ. 2013:91:671-682D.

32. Fezeu L, Balkau B, Sobngwi E, Kengne AP, Vol S, Ducimetiere P, et al. Waist circumference and obesity-related abnormalities in French and Cameroonian adults: the role of urbanization and ethnicity. Int J Obes. 2010;34:446-53.

33. Bazzano LA, Li TY, Joshipura KJ, Hu FB. Intake of fruit, vegetables, and fruit juices and risk of diabetes in women. Diabetes Care. 2008;31:1311-7.

34. Villegas R, Shu XO, Gao YT, Yang, Elasy T, Li H, et al. Vegetable but not fruit consumption reduces the risk of type 2 diabetes in Chinese women. J Nutr. 2008;138:574-80

35. Beulens JW, van der Schouw YT, Bergmann MM, Rohrmann S, Schulze MB, Buijsse $B$, et al. Alcohol consumption and risk of type 2 diabetes in European men and women: influence of beverage type and body size. The EPIC-inter act study. J Intern Med. 2012;272(4):358-70.

36. Helmrich SP, Ragland DR, Leung RW, Paffenbarger Jr RS. Physical activity and reduced occurrence of non-insulin-dependent diabetes mellitus. $\mathrm{N}$ Engl J Med. 1991:325:147-52.

37. Helmrich SP, Ragland DR, Paffenbarger Jr RS. Prevention of non-insulindependent diabetes mellitus with physical activity. Med Sci Sports Exerc 1994;26:824-30

38. Hu G, Qiao Q, Silventoinen K, Eriksson JG, Jousilahti P, Lindström J, et al. Occupational, commuting, and leisure-time physical activity in relation to risk for type 2 diabetes in middle-aged Finnish men and women. Diabetologia. 2003;46(3):322-9.

\section{Submit your next manuscript to BioMed Central and take full advantage of:}

- Convenient online submission

- Thorough peer review

- No space constraints or color figure charges

- Immediate publication on acceptance

- Inclusion in PubMed, CAS, Scopus and Google Scholar

- Research which is freely available for redistribution 